CLINICAL STUDY

\title{
Long-term clinical data and molecular defects in the STAR gene in five Greek patients
}

Amalia Sertedaki, Maria Dracopoulou, Antonis Voutetakis, Kalliopi Stefanaki ${ }^{1}$, Dimitra Rontogianni ${ }^{2}$, Alexandra-Maria Magiakou, Christina Kanaka-Gantenbein, George Chrousos and Catherine Dacou-Voutetakis

Division of Endocrinology, Diabetes and Metabolism, First Department of Pediatrics, 'Agia Sophia' Children's Hospital, Athens University School of Medicine, Athens, Greece, ' Department of Pathology, 'Agia Sophia' Children's Hospital, Athens, Greece and ${ }^{2}$ Department of Pathology, Evangelismos Hospital, Athens, Greece

(Correspondence should be addressed to C Dacou-Voutetakis; Email: adacou@med.uoa.gr)

\begin{abstract}
Context: Steroidogenic acute regulatory $(S T A R)$ gene mutations lead to adrenal and gonadal failure. Interesting, though as yet unexplained, features are the formation of ovarian cysts and the potential presence of CNS findings.

Objective: To report biochemical, genetic, and long-term clinical data in five Greek patients from four different families with STAR gene defects (three 46,XX and two 46,XY).

Methods and results: All patients presented in early infancy with adrenal insufficiency. The STAR gene mutation c.834del11bp, detected in three of our patients, completely alters the carboxyl end of the STAR protein and has not thus far been described in other population groups. These three patients belong to three separate families, possibly genetically related, as they live in different villages located in a small region of a Greek island. However, their interrelationship has not been proven. A second mutation, p.W250X, detected in our fourth family, was previously described only in two Serbian patients. Ovarian cysts were detected ultrasonographically in our 46,XX patients and seemed to respond to a low dose of a contraceptive. The histology of an excised ovarian cyst was diagnosed as a corpus luteum (CL) cyst. In two out of the four patients who had undergone brain magnetic resonance imaging, asymptomatic Chiari-1 malformation was observed.

Conclusions: The occurrence of STAR gene mutation c.834del11bp in three families living in a restricted geographic region could indicate either a founder effect or simply reflect a spread of this defect in a highly related population. The ovarian histological findings suggest that ovarian cysts detected ultrasonographically in 46,XX individuals with STAR gene defects may be CL cysts. The Chiari-1 malformation in two of our patients may be part of the STAR gene mutation phenotype. Nevertheless, more data are needed to confirm or disprove the existence of specific CNS pathology in patients with STAR gene mutations.
\end{abstract}

European Journal of Endocrinology 168 351-359

\section{Introduction}

Steroidogenic acute regulatory (STAR) protein mediates the transfer of cholesterol from the outer to the inner mitochondrial membrane. This process provides the substrate for the initiation of steroidogenesis and constitutes a rate-limiting step in the acute response of steroidogenic cells of the adrenal cortex and the gonads to the corresponding tropic hormones. The gene encoding the STAR protein mapped on chromosomal locus 8p11.2 consists of seven exons and six introns and is expressed in the adrenal cortex and the gonads but not in the placenta $(1,2,3,4)$. Interestingly, STAR is also expressed in other tissues, including the brain $(5,6)$. Most mutations of the STAR gene are located in exons 5-7, affecting the STAR-related lipid transfer domain (START), resulting in a drastic reduction of STAR cholesterol transfer activity, while deletion of 28 carboxyl terminal residues suppresses all activity $(7,8,9)$.

Mutations in the STAR gene lead to a defect at an early step of steroidogenesis, resulting in severe adrenal insufficiency and gonadal failure (congenital lipoid adrenal hyperplasia (CLAH)), usually manifested in infancy $(3,4,9)$. There have been cases, however, characterized by late onset of adrenal failure and normal male genitalia $(10,11)$ or by a phenotype that could be misinterpreted as familial glucocorticoid deficiency $(12,13)$.

Adrenal insufficiency does not differ in $46, \mathrm{XY}$ and 46, XX individuals with STAR gene mutations, while the gonadal defect shows gender dimorphism. Thus, testicular failure is manifested antenatally, leading to sex reversal in most cases, whereas ovarian function 
is normal for many years, leading to normal puberty and menarche but premature menopause $(14,15,16$, $17,18)$. We herein present long-term data of five Greek patients with STAR gene mutations.

\section{Materials and methods}

\section{Patients}

Six patients belonging to four families were admitted to our center in infancy with vomiting, failure to thrive, electrolyte abnormalities, low cortisol and androgen values, and high corresponding ACTH values, with initial diagnosis being primary adrenal insufficiency. Clinical and biochemical characteristics of all patients are shown in Tables 1 and 2.

Family 1 Patient 1, a female, now aged 30 years, was examined at the age of 8 months because of vomiting and failure to thrive since the age of 4 months and was diagnosed with adrenal insufficiency (Table 1). The first child of the family had presented with vomiting and dehydration and died at the age of 3 months. Two other siblings are healthy. On replacement therapy with hydrocortisone and $9 \alpha$-fludrocortisone, the patient grew well, reaching a final height of $160 \mathrm{~cm}$ (SDS, -0.6; target height (TH) SDS, -0.2). Breast Tanner II stage was noted at 9 years and menarche at 12 years. She married at the age of 16 years. Up to the age of 24 years, she could not conceive. An ovarian cyst was detected sonographically at the age of 20 years during a workup for infertility (Fig. 1A) and was excised before the STAR gene mutation diagnosis (see histology in the Results section). At the age of 24 years, molecular genetic analysis revealed the presence of STAR gene mutation. As the same mutation was detected in her husband in the heterozygous state, she underwent IVF and preimplantation diagnosis and gave birth to a normal girl (19). Following her pregnancy, menses were irregular and ovarian cysts were again detected on ultrasonography (U/S). On half dose of a contraceptive (estrogen content $20 \mu \mathrm{g}$ ), the ovarian cysts disappeared and reappeared whenever the patient herself interrupted treatment.
Family 2 Patient 2, a female, now aged 28 years, was first examined at the age of 2 months and diagnosed with adrenal insufficiency (Table 1). On replacement therapy with hydrocortisone and $9 \alpha$-fludrocortisone, she grew well and reached a final height of $162 \mathrm{~cm}$ (SDS, - 0.2; TH SDS, - 1). Breast development started at age 11 years and menarche occurred at age 13 years. Pelvic U/S at age 5 years showed normal-for-age ovarian size. Ovarian cysts were first detected at 19.5 years during a workup for menstrual irregularities. Molecular genetic analysis revealed the presence of STAR gene mutation. Patient 3, a phenotypic female, was diagnosed with adrenal insufficiency and microcephaly at the age of 3 months and replacement therapy for the adrenal failure was initiated. Nevertheless, the infant died at the age of 14 months at home. Unfortunately, no details are available; no autopsy or molecular genetic analysis was carried out, but a STAR gene mutation is strongly suspected. Four other children in this family (three males and one female) are healthy, but they declined the molecular genetic analysis.

Family 3 Patient 4, a female, now aged 19.5 years, was first examined on the 20th day of life and diagnosed with adrenal insufficiency (Table 1). On replacement therapy with hydrocortisone and $9 \alpha$-fludrocortisone, she has been well and reached a final height of $154.5 \mathrm{~cm}$ (SDS, -1.7 ; TH SDS, -1.8). At the age of 6.6 years, as well as at 12.1 years, the ovaries were sonographically normal. Thelarche and pubarche Tanner stage II were noted at the age of 13 years, at which time ovarian cysts were first identified (Fig. 1B). She was then started on a contraceptive regimen (estrogen content $20 \mu \mathrm{g}$ ), and 1 month later, the ovaries were of normal size and architecture. After 1 month, the contraceptive pill was discontinued and an ovarian cyst was detected on the left ovary. Normal ovaries were seen soon after resumption of the contraceptive pill. At the age of 14.5 years, half dose of the contraceptive regimen (estrogen content $20 \mu \mathrm{g}$ ) was initiated, and during 6 years on this regimen, no cysts have developed, while she has regular vaginal bleeding. A brain magnetic resonance imaging (MRI) at age 19 years disclosed Chiari-1 malformation. No neurological deficit has been

Table 1 Biochemical, hormonal, and sonographic data of the patients with STAR gene mutations at diagnosis. Normal values are shown in parenthesis.

\begin{tabular}{llllll}
\hline & Patient 1 & Patient 2 & Patient 4 & Patient 5 & Patient 6 \\
\hline Age at diagnosis (months) & 8 & 2 & 0.7 & 0.8 & 0.5 \\
Serum Na (mmol/l) (138-150) & 115 & 135 & 115 & 106 & 127 \\
Serum K (mmol/l) (3.5-5.5) & 8.0 & 7.5 & 7.3 & 6.9 & 7.7 \\
Cortisol baseline (nmol/l) (138-552) & Undetectable & 74.5 & 300.8 & 350 & 187.7 \\
Cortisol post ACTH (nmol/l) (>500) & NA & 36 & NA & NA & NA \\
ACTH (pmol/l) (1.1-13.2) & NA & NA & 455 & $>341$ & $>330$ \\
17OH progesterone (nmol/l) & $6.9(0.7-4.7)$ & NA & $0.9(2.5-12.6)$ & $1.5(2.5-12.6)$ & $1.5(2.5-12.6)$ \\
Adrenal sonography & Not visualized & NA & NA & 'Normal' & 'Normal' \\
\hline
\end{tabular}

NA, not available. 


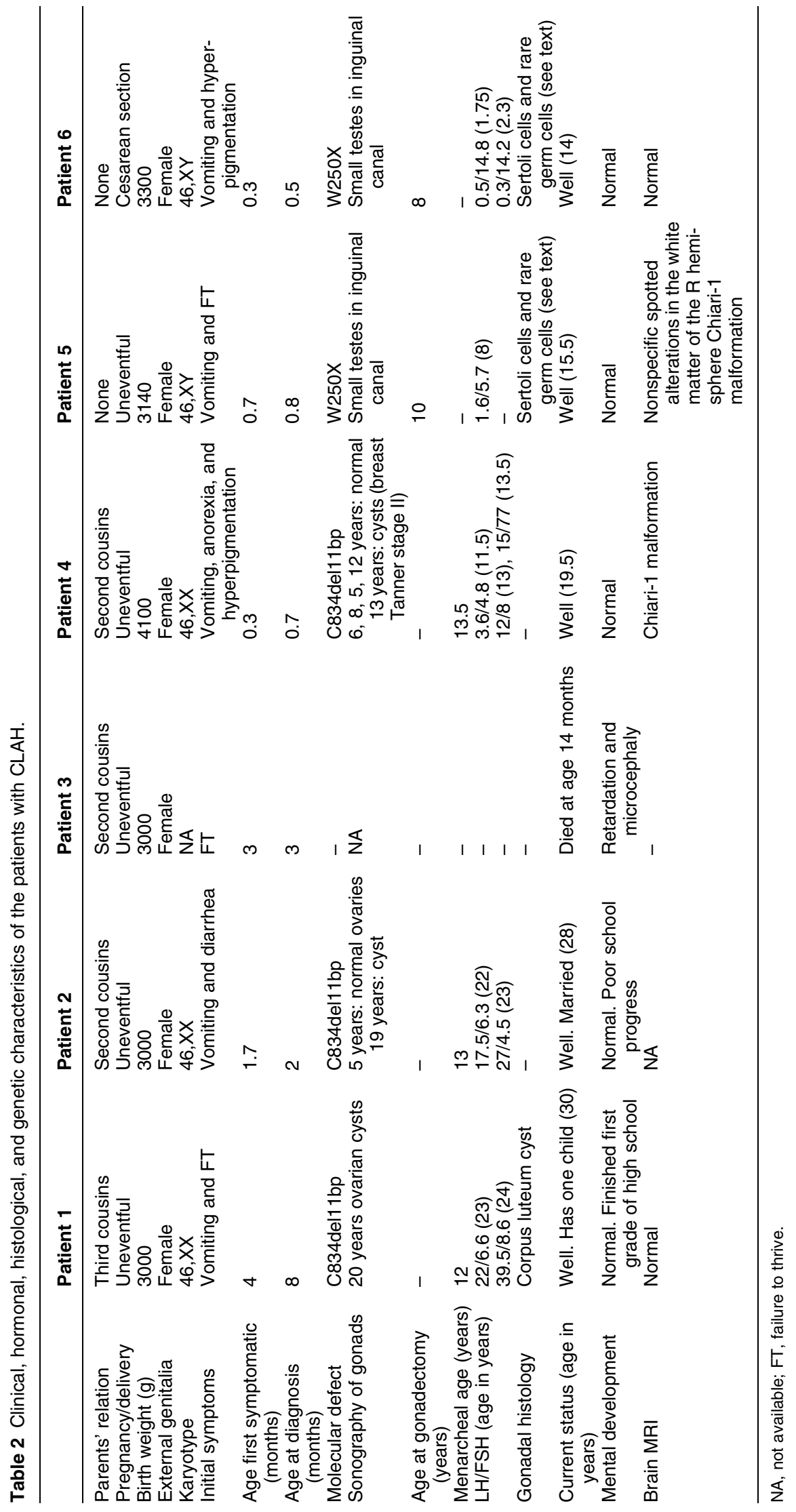




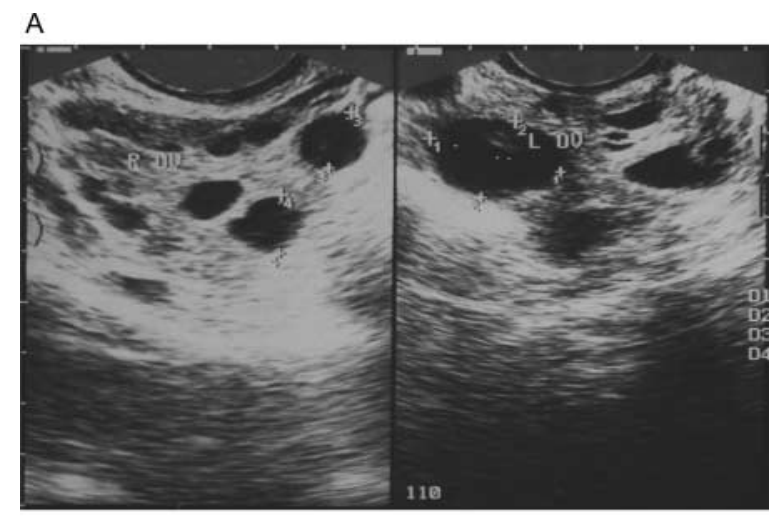

B

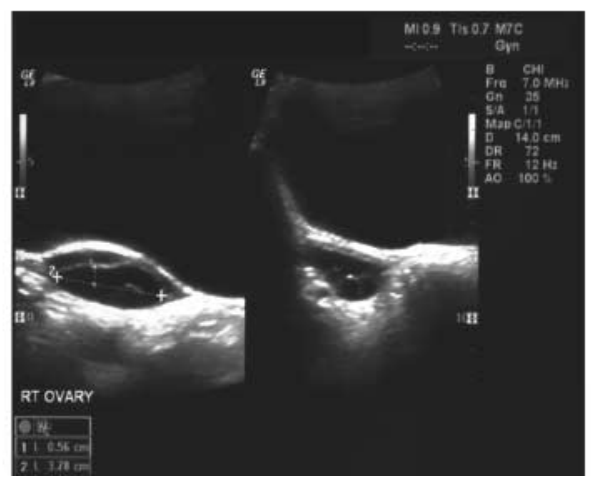

Figure 1 (A) Ovarian ultrasonography of patient 1 showing multiple cysts in both ovaries at the age of 20 years. (B) Ovarian ultrasonography of patient 4 showing a cystic allantoid structure across the entire length of the right ovary.

detected, but her school progress has been poor. Molecular genetic analysis revealed the presence of STAR gene mutation. One older male sibling is healthy but declined molecular genetic analysis.

Family 4 Patient 5 was admitted at the age of 25 days and diagnosed with adrenal insufficiency (Table 1). The external genitalia had normal female appearance. However, the pelvic U/S revealed gonads in the inguinal canal, which resembled testes, and no uterus was identified. The karyotype was 46,XY. At the age of 12 months, a human chorionic gonadotrophin test demonstrated no response of testosterone and its precursors, revealing an additional defect in testicular steroidogenesis. At the age of 10 years, gonadectomy was carried out (see histology in the Results section). The patient, now aged 15.5 years, is well and growing normally on replacement therapy with hydrocortisone and $9 \alpha$-fludrocortisone. A brain MRI at the age of 12 years disclosed a Chiari-1 malformation and nonspecific spotted alterations in the white matter of the right cerebral hemisphere. Clinically, the patient had no neurological deficits and the school progress has reportedly been average.

Patient 6 , a sibling of patient 5 , was admitted at the age of 16 days and diagnosed with adrenal insufficiency
(Table 1). Although a phenotypic female, pelvic ultrasonography disclosed no uterus, while gonads resembling testes $\left(0.1 \mathrm{~cm}^{3}\right)$ were present in the inguinal canal. The karyotype was 46,XY. Gonadectomy was carried out at the age of 8 years. The patient, now aged 14 years, has been doing well on replacement therapy with hydrocortisone and $9 \alpha$-fludrocortisone. A brain MRI carried out at age 10 years revealed no pathological findings and the school progress was reported as good. Molecular genetic analysis revealed a STAR gene mutation in both patients 5 and 6 .

\section{Methods}

DNA sequencing analysis DNA was extracted from peripheral blood leucocytes using the QIAamp DNA Blood mini kit (Qiagen) after informed consent was obtained from the parents that genetic analysis be carried out. The seven exons and their flanking intronic sequences of the STAR gene (Ensembl Transcript ID, ENST00000276449) were PCR amplified and directly sequenced on an automated sequencer (ABI 3100 Avant, Applied Biosystems). The PCR and sequencing primers were designed using the Primer 3 (v.0.4.0) program and are available on request.

Immunohistochemical studies Tissue sections from the ovarian cysts and the testes, formalin fixed and paraffin embedded, were stained with hematoxylineosin. The Bond Polymer Detection Kit (Vision Biosystems, Norwell, MA, USA) was used on paraffin sections for the detection of inhibin $\alpha$ subunit (Biocare Medical, Concord, CA, USA, 1/100), calretinin (Novocastra (Newcastle, UK), 1/150), placentalike alkaline phosphatase (PLAP; DAKO (Glostrup, Denmark), 1/50), progesterone receptor (Spring Bioscience (Pleasanton, CA, USA), SP2 1/40), and Melan-A (Novocastra, 1/50). Melan-A, a product of the MART1 (MLANA) gene, is an antigen recognized by antibody A103, and although its primary utility is in the identification of melanoma cells, it also stains steroid-producing cells. Control experiments with anti-peptides were conducted to show specificity of the antibodies.

Hormonal studies LH, FSH, cortisol, and ACTH were measured by electrochemiluminescent immunoassays on a Cobas e411 automatic analyzer (Roche Diagnostics GmbH (Mannheim, Germany); precision CV: LH $1.1 \%$, FSH $1.7 \%$, cortisol $1.2 \%$, and ACTH $2.3 \%$ ). Testosterone was measured by chemiluminescent immunoassay on an Immulite 2000 automatic analyzer (Siemens Healthcare Diagnostics, Tarrytown, NY, USA; precision CV: 9.5\%). 17OHP was determined by RIA employing reagents from ICN Pharmaceuticals, Inc. (Costa Mesa, CA, USA; precision CV: 9.1\%). 


\section{Results}

Hormonal data are depicted in Table 1. Patients 1, 2, and 4 (Families 1, 2, and 3) were shown to be homozygotes and their parents were heterozygotes for the deletion c.834del11bp (p.K236delfsX43) in exon 6 of the STAR gene (Table 2, Fig. 2). This 11 bp deletion results in a frameshift, which alters the carboxyl end of the protein, from amino acid 235 onward. It also creates a new stop codon at amino acid 278, making the protein shorter than the wild type by seven amino acids (Fig. 2). The three families that harbor the $11 \mathrm{bp}$ deletion reside in different villages located in a small region of the island of Crete. In all three families, the parents were second- or thirddegree relatives. However, the interrelationships between the three families are not known.

In both 46,XY siblings of Family 4 (patients 5 and 6), the mutation p.W250X was detected (Table 2). The parents, heterozygotes for the p.W250X mutation,

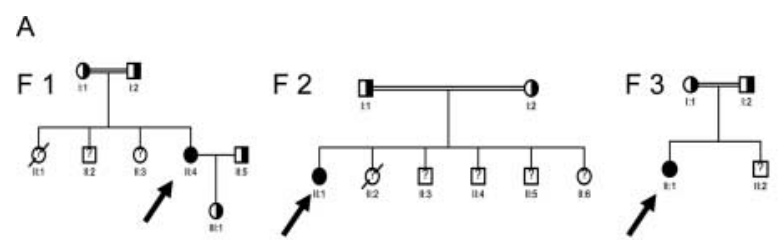

B

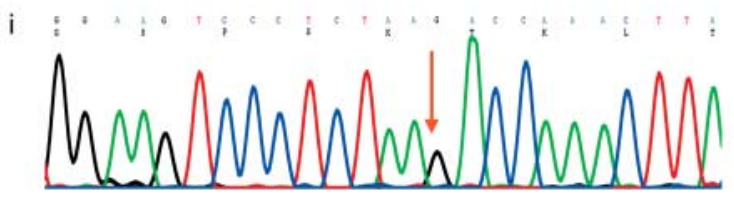

ii

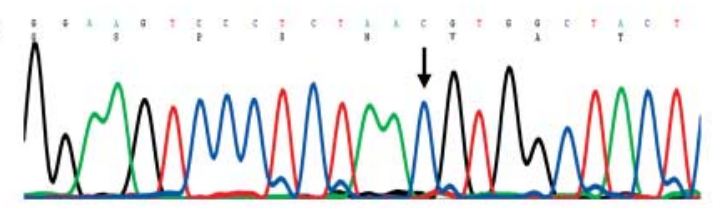

iii

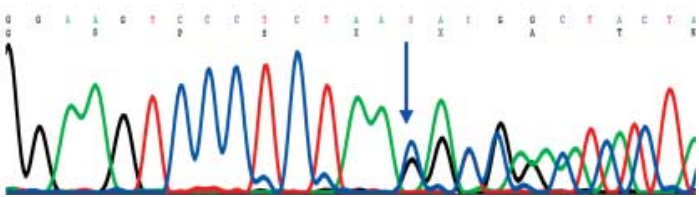

Figure 2 Family trees and partial sequence chromatograms of STAR gene. (A) F1, family 1, patient 1; F2, family 2, patients 2 and 3; F3, family 3 , patient 4 . Black symbols and arrows indicate the affected probands. (B) Partial sequence chromatograms of exon 6 of the STAR gene. (i) wild type; (ii) homozygote for the $11 \mathrm{bp}$ deletion c.834del11bp; and (iii) heterozygote for the $11 \mathrm{bp}$ deletion c.834del11bp. The arrows indicate the nucleotide at which the deletion starts; red for wild type, black for homozygote, and blue for heterozygote.
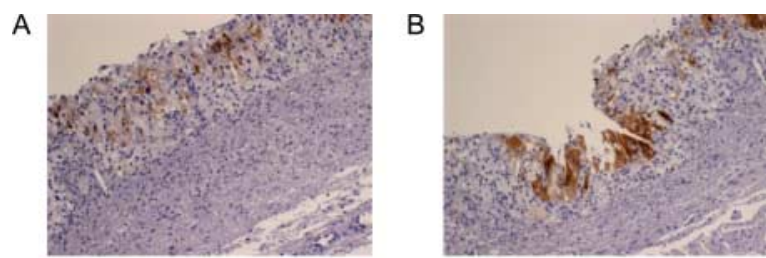

C

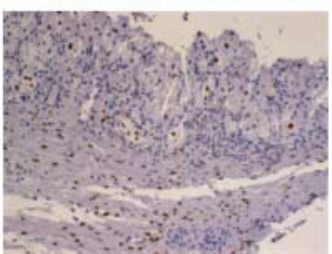

Figure 3 Histology of the excised ovarian cyst of patient 1. (A) Cytoplastic focal distribution of Melan-A, (B) cytoplastic focal distribution of inhibin $\alpha$ subunit, and (C) immunostaining of progesterone receptors in a moderate number of cells of the cyst and the stroma, Envision $\times 200$. These sections represent typical findings from the wall of the cyst.

originated from the island of Rhodes but mentioned no consanguinity.

The ovarian cyst excised from patient 1 (Family 1) was shown to be a corpus luteum (CL) cyst. Specifically, the immunohistochemical analysis disclosed: i) cytoplasmic focal distribution of Melan-A (a marker of steroid-producing cells); ii) cytoplasmic focal distribution of inhibin $\alpha$ subunit indicating the presence of granulosa cells; and iii) immunostaining of progesterone receptors in a moderate number of cells of the cyst and the stroma (Fig. $3 \mathrm{~A}, \mathrm{~B}$ and C).

The histological studies of the testes removed from patient 5 (Fig. 4 A, B and C) revealed prepubertal testes at a static stage of development, consisting of testicular tubules with Sertoli cells and rare germ cells some of which were large. The Sertoli cells had a focal vesicular appearance. A significant number of Leydig cells were observed in the interstitial tissue with microvesicular appearance. The immunohistochemical study showed positive staining for inhibin $\alpha$ subunit as well as Melan-A and calretinin expression (Melan-A and Calretinin are markers expressed in Leydig cells; calretinin data not shown). PLAP was not identified in the isolated spermatogonia. There was no evidence of intratubular germ cell neoplasia. The only difference observed between patient 6 and his sibling (patient 5; Family 4) was the lower number of Leydig cells in the interstitial stroma containing microvesicular vacuoles. The MRI results are depicted in Table 2 and in patients' descriptions.

\section{Discussion}

The majority of reported STAR gene mutations are located in exons 5-7. Various studies have shown that the C-terminal region of the STAR protein is important for cholesterol transfer and, hence, for steroid 


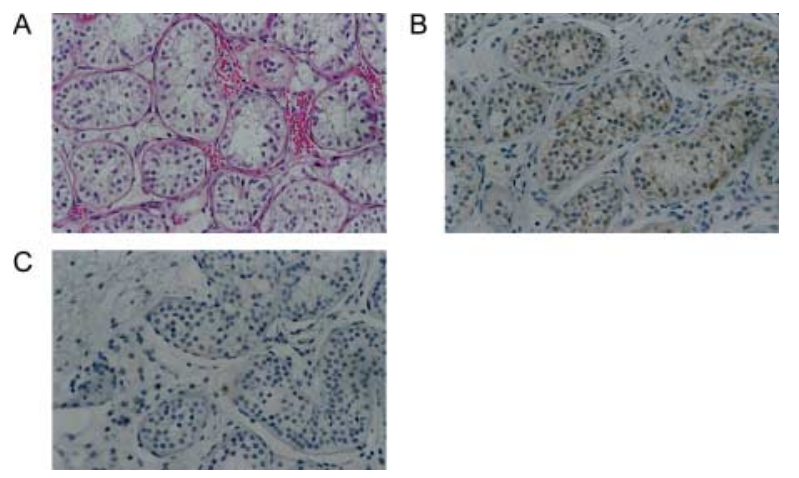

Figure 4 Histology of the testes of patient 5 at the age of 10 years. (A) Spermatic tubules of prepubertal testis with Sertoli cells and vesicular Leydig cells possibly due to lipid droplets or degeneration (hematoxylin-eosin $\times 200$ ), (B) immunohistochemical expression of inhibin $\alpha$ subunit in the Sertoli cells (streptavidin-biotin-HRP $\times 200$ ), and $(C)$ immunohistochemical expression of Melan-A in vesicular Leydig cell (streptavidin-biotin-HRP $\times 200$ ).

biosynthesis $(1,2,3,20,21,22)$. The 11 bp deletion (c.834del11bp, p.K236delfsX43) detected in our three 46 ,XX patients has not thus far been identified in other population groups. These patients belong to three separate families, reportedly not related and living in different villages located in a small geographic region of the island of Crete. These data possibly indicate either a founder effect or simply a spread of this molecular defect in a highly related population. The mutation p.W250X, detected in the two 46,XY siblings (patients 5 and 6), was previously reported in two $46, \mathrm{XY}$ phenotypically female Serbian patients $(11,23)$. The parents of patients 5 and 6 originated from the island of Rhodes but no consanguinity was reported.

In general, mutations in the STAR gene usually lead to a classic form of the disease characterized by earlyonset adrenal insufficiency and gonadal failure, the latter showing gender dimorphism both in severity and in time of onset. Most affected 46,XY patients fail to masculinise, whereas the affected 46,XX individuals reported thus far have had normal pubertal development and menarche at the appropriate age $(14,15,16)$.

Large cysts of the ovaries have been reported in 46,XX individuals with STAR gene defects $(15,16)$. In our two older patients, ovarian cysts were first identified around the age of 20 years during a workup for either irregular menses or infertility before the specific molecular diagnosis. In one of them (patient 2), earlier ovarian sonography at the age of 5 years was normal. In the younger patient of our cohort (patient 4), with an early diagnosis of STAR gene mutation, ovarian sonography was carried out at a younger age and at frequent intervals. In this patient, an ovarian cyst was first detected at 13 years and at pubertal Tanner stage II. An analogous observation of normal ovaries at prepubertal stage was reported in a girl, aged 8 years, with CLAH (24). These findings indicate that cysts might not be present before puberty but appear with the rise of gonadotropins, i.e. at a stage of higher functional demands when initiation of follicle recruitment occurs.

The mechanism of ovarian cyst formation in girls with STAR gene mutations remains an enigma (25), and especially the proneness to recurrence, as was illustrated in patient 4 . The mechanism of an increased LH/FSH ratio $(25,26)$, also detected in our $46, \mathrm{XX}$ patients, and its relation to cyst formation is not clear. In a failing ovary, a high FSH/LH ratio is found, whereas an increased LH/FSH ratio is detected in women with polycystic ovary syndrome (27). The analogy between the latter entity and the 46,XX women with STAR gene mutations regarding the LH/FSH ratio is not apparent. It must be mentioned, however, that targeted overexpression of LH in transgenic mice leads to infertility, ovarian cyst formation, and enlarged ovaries (28).

The histological data of the ovarian cyst, surgically excised from patient 1 at the age of 20 years, indicate CL cyst. The CL is a 'temporary endocrine organ' producing steroids for which the STAR gene is required $(29,30)$. In an infertile cycle, the CL undergoes a process of regression known as luteolysis. We may thus assume that in 46,XX women with STAR gene mutations, ovulation takes place but the function of the CL is impaired, this possibly leading to cyst formation, as well as to low progesterone synthesis, and infertility. Only one previous report described histological findings from the ovary of a 22-year-old woman, which, however, had undergone torsion. In that particular case, the expected decrease in steroidogenesis was demonstrated by histochemical studies. No CL was detected, while corpus albicans, a regressed form of CL, was present. In STAR knockout mice, no CL was found (31).

The role of ovarian cysts in causing 'mechanical damage' to the ovary is not known, but such an effect is theoretically expected. We must emphasize that ovarian torsion has been reported in 46,XX subjects with STAR gene mutations $(26,32)$. Hence, early recognition and management of ovarian cysts is imperative. Most likely, by prompt suppressive therapy of gonadotropin secretion, depletion of normal follicles and the presumed mechanical damage from ovarian cysts could be prevented and thus normal ovarian architecture and potential for fertility may be preserved for longer periods. It is quite possible that half dose of the low estrogen pill might prove effective, as demonstrated by the course of events in our patients 1 and 4 . A limited number of successful pregnancies of patients with STAR gene mutations have been reported $(19,33)$.

The synthesis of data related to testicular histology in STAR patients, both from the literature $(34,35,36,37$, $38,39)$ and those of our patients, indicate that at an early development stage (fetal and early postnatal life), the testes have normal architecture and a normal number of germ cells, whereas Leydig cells are either scattered or absent. It appears that germ cells are normal prenatally and in early postnatal life but 
decrease in number and become large later on. This observation indicates that although germ cells follow a different lineage than steroidogenic cells of the testis, endogenous testosterone production is required for normal germ cell evolution and maintenance. It must be mentioned that testicular biopsy in a 36-year-old male with mild STAR gene mutation, investigated for infertility, showed partial atrophy with interstitial fibrosis, many Reincke crystalloids (confirming the presence of Leydig cells), and reduced spermatogenesis (12). In a 15-year-old patient (23), a carcinoma in situ was detected in the excised testis. Moreover, in a 1-yearold patient, the excised testes showed positive PLAP and octamer binding transcription factor staining, indicative of neoplastic potential (39). This information is of considerable interest and should be considered when deciding the timing of gonadectomy.

The CNS findings in two of our patients are intriguing. STAR protein, a key factor in steroidogenesis, is widely expressed in the brain and specifically in neurons, glial cells, and proliferating precursors $(5,6,8)$ and therefore STAR gene defects could lead to CNS malfunction. Nevertheless, thus far, convincing evidence for the existence of impaired brain function or structure in CLAH patients is lacking $(20,39)$. A possible interpretation could be the following: i) brain steroidogenesis is not essential for brain formation and/or function in humans; and ii) a search for pertinent brain pathology has not been systematically carried out to uncover possible defects. Specifically, brain MRI scans or cognitive and other related studies have not been performed systematically in an adequately large number of CLAH patients to offer reliable data.

To our knowledge, of the few children with STAR gene mutations in whom an MRI was performed, Chiari-1 malformation was detected in one. In two of our four patients in whom a brain MRI was carried out, Chiari-1 malformation was detected. Other CNS abnormalities have also been detected in such patients, like frontal and temporal lobe atrophy, supratentorial white matter lesions, mental retardation, and hemiatrophy of the right cerebrum, which, however, could have been caused by electrolyte abnormalities in early postnatal life.

The exact prevalence of Chiari-1 malformation in the general population remains unknown. In a study carried out in a general population sample of individuals younger than 20 years $(n=5248)$, the prevalence of Chiari-1 malformation was $0.7 / 10.000$, whereas in subjects who had an MRI for CNS symptoms, it was $1 \%$ (40). Of note is the report that $37 \%$ of the subjects with Chiari-1 younger than 20 years were asymptomatic at the time of diagnosis, as were our two patients with Chiari-1 malformation. Thus, the existence of CNS pathology (functional or morphologic) in this nosologic entity remains uncertain. Obviously, data from a systematic study with brain MRI scans even in asymptomatic patients and pertinent functional studies in a significant number of patients with STAR gene mutations might offer a satisfactory answer to the questions raised above.

In conclusion, the mutation c.834del11bp has thus far been identified only in our three patients who belong to different families living in a restricted geographic region. The p.W250X mutation detected in two 46, XY siblings from the island of Rhodes has previously been reported only in two Serbian patients. The Chiari-1 malformation in two of our patients may be part of the STAR gene mutation phenotype. Nevertheless, further studies are needed to confirm or disprove CNS pathology in patients with STAR gene mutations. The histological findings of an excised ovarian cyst, indicating a CL cyst, represent a novel observation with implications for the elucidation of the pathophysiology involved in ovarian cyst formation in this entity. An estrogen-progesterone regimen at half the usual dose, initiated at puberty, may preserve normal ovarian architecture and fertility for longer periods.

\section{Declaration of interest}

The authors declare that there is no conflict of interest that could be perceived as prejudicing the impartiality of the research reported.

\section{Funding}

This research did not receive any specific grant from any funding agency in the public, commercial or not-for-profit sector.

\section{Acknowledgements}

The authors thank Dr F Prodromou, Head of Neurosurgery Department, Agia Sophia Children's Hospital, for reviewing the MRIs of the patients.

\section{References}

1 Sugawara T, Holt JA, Driscoll D, Strauss JF III, Lin D, Miller WL, Patterson D, Clancy KP, Hart IM, Clark BJ et al. Human steroidogenic acute regulatory protein: functional activity in COS-1 cells, tissue-specific expression, and mapping of the structural 378 gene to $8 \mathrm{p} 11.2$ and a pseudogene to chromosome 13. PNAS 199592 4778-4782. (doi:10.1073/pnas.92.11.4778)

2 Lin D, Sugawara T, Strauss JF III, Clark BJ, Stocco DM, Saenger P, Rogol A \& Miller WL. Role of steroidogenic acute regulatory protein in adrenal and gonadal steroidogenesis. Science 1995267 1828-1831. (doi:10.1126/science.7892608)

3 Bose HS, Sugawara T, Strauss JF III \& Miller WL. The pathophysiology and genetics of congenital lipoid adrenal hyperplasia. New England Journal of Medicine 1996335 1870-1878. (doi:10.1056/NEJM199612193352503)

4 Nakae J, Tajima T, Sugawara T, Arakane F, Hanaki K, Hotsubo T, Igarashi N, Igarashi Y, Ishii T, Koda $\mathrm{N}$ et al. Analysis of the steroidogenic acute regulatory protein (StAR) gene in Japanese patients with congenital lipoid adrenal hyperplasia. Human Molecular Genetics 19976 571-576. (doi:10.1093/hmg/6.4.571)

5 King SR, Manna PR, Ishii T, Syapin PJ, Ginsberg SD, Wilson K, Walsh LP, Parker KL, Stocco DM, Smith RG et al. An essential component in steroid synthesis, the steroidogenic acute regulatory protein, is expressed in discrete regions of the brain. Journal of Neuroscience 200222 10613-10620. 
6 Kim HJ, Kang SS, Cho GJ \& Choi WS. Steroidogenic acute regulatory protein: its presence and function in brain neurosteroidogenesis. Archives of Histology and Cytology 200467 383-392. (doi:10.1679/aohc.67.383)

7 Wang X, Liu Z, Eimerl S, Timberg R, Weiss AM, Orly J \& Stocco DM. Effect of truncated forms of steroidogenic acute regulatory protein on intramitochondrial cholesterol transfer. Endocrinology 1998 139 3903-3912. (doi:10.1210/en.139.9.3903)

8 Caron KM, Soo SC, Wetsel WC, Stocco DM, Clark BJ \& Parker KL. Targeted disruption of the mouse gene encoding steroidogenic acute regulatory protein provides insights into congenital lipoid adrenal hyperplasia. PNAS $1997 \quad 94 \quad 11540-11545$. (doi:10.1073/pnas.94.21.11540)

9 King SR, Bhangoo A \& Stocco DM. Functional and physiological consequences of StAR deficiency: role in lipoid congenital adrenal hyperplasia. Endocrine Development 201120 47-53. (doi:10.1159/000321214)

10 Baker BY, Lin L, Kim CJ, Raga J, Smith CP, Miller WL \& Achermann JC. Nonclassic congenital lipoid adrenal hyperplasia: a new disorder of the steroidogenic acute regulatory protein with very late presentation and normal male genitalia. Journal of Clinical Endocrinology and Metabolism 200691 4781-4785. (doi:10.1210/jc.2006-1565)

11 Sahakitrungruang T, Soccio RE, Lang-Muritano M, Walker JM, Achermann JC \& Miller WL. Clinical, genetic, and functional characterization of four patients carrying partial loss-of-function mutations in the steroidogenic acute regulatory protein (StAR). Journal of Clinical Endocrinology and Metabolism $2010 \quad 95$ 3352-3359. (doi:10.1210/jc.2010-0437)

12 Metherell LA, Naville D, Halaby G, Begeot M, Huebner A, Nürnberg G, Nürnberg P, Green J, Tomlinson JW, Krone NP et al. Nonclassic lipoid congenital adrenal hyperplasia masquerading as familial glucocorticoid deficiency. Journal of Clinical Endocrinology and Metabolism 200994 3865-3871. (doi:10.1210/jc.20090467)

13 Flück CE, Pandey AV, Dick B, Camats N, Fernández-Cancio M, Clemente M, Gussinyé M, Carrascosa A, Mullis PE \& Audi L. Characterization of novel StAR (steroidogenic acute regulatory protein) mutations causing non-classic lipoid adrenal hyperplasia. PLoS ONE 201165 e20178. (doi:10.1371/journal.pone. 0020178)

14 Bose HS, Sato S, Aisenberg J, Shalev SA, Matsuo N \& Miller WL. Mutations in the steroidogenic acute regulatory protein (StAR) in six patients with congenital lipoid adrenal hyperplasia. Journal of Clinical Endocrinology and Metabolism $2000 \mathbf{8 5}$ 3636-3639. (doi:10.1210/jc.85.10.3636)

15 Bose HS, Pescovitz OH \& Miller WL. Spontaneous feminization in a $46, \mathrm{XX}$ female patient with congenital lipoid adrenal hyperplasia due to a homozygous frameshift mutation in the steroidogenic acute regulatory protein (StAR) gene. Journal of Clinical Endocrinology and Metabolism 199782 1511-1515. (doi:10.1210/jc. 82.5.1511)

16 Fujieda K, Tajima T, Nakae J, Sageshima S, Tachibana K, Suwa S, Sugawara T \& Strauss JF III. Spontaneous puberty in 46,XX subjects with congenital lipoid adrenal hyperplasia. Ovarian steroidogenesis is spared to some extent despite inactivating mutations in the steroidogenic acute regulatory protein (StAR) gene. Journal of Clinical Investigation 199799 1265-1271. (doi:10.1172/JCI119284)

17 Bhangoo A, Buyuk E, Oktay K \& Ten S. Phenotypic features of 46,XX females with StAR protein mutations. Pediatric Endocrinology Reviews 20075 633-641.

18 Bens S, Mohn A, Yuksel B, Kulle AE, Michalek M, Chiarelli F, Nuri Ozbek M, Leuschner I, Grötzinger J, Holterhus PM et al. Congenital lipoid adrenal hyperplasia: functional characterization of three novel mutations in the StAR gene. Journal of Clinical Endocrinology and Metabolism 2010 95 1301-1308. (doi:10.1210/jc.2009-1176)

19 Sertedaki A, Pantos K, Vrettou Ch, Kokkali G, Christoforidou Ch, Kanavakis E \& Dacou-Voutetakis C. Conception and pregnancy outcome in a patient with 11 bp 435 deletion of the steroidogenic acute regulatory protein (StAR) gene. Fertility and Sterility 2009 91 934.e15-934.e18. (doi:10.1016/j.fertnstert.2008.07.1770)

20 Bhangoo A, Gu WX, Pavlakis S, Anhalt H, Heir L, Ten S \& Jameson JL. Phenotypic features associated with mutations in steroidogenic acute regulatory protein. Journal of Clinical Endocrinology and Metabolism 200590 6303-6309. (doi:10.1210/jc. 2005-0434)

21 Arakane F, Sugawara T, Nishino H, Liu Z, Holt JA, Pain D, Stocco DM, Miller WL \& Strauss JF III. Steroidogenic acute regulatory protein (StAR) retains activity in the absence of its mitochondrial import sequence: implications for the mechanism of StAR action. PNAS 199693 13731-13736. (doi:10.1073/ pnas.93.24.13731)

22 Tsujishita Y \& Hurley JH. Structure and lipid transport mechanism of a StAR-related domain. Nature Structural $\mathcal{E}$ Molecular Biology 2000 7 408-414. (doi:10.1038/75192)

23 Korsch E, Peter M, Hiort O, Sippell WG, Ure BM, Hauffa BP \& Bergmann M. Gonadal histology with testicular carcinoma in situ in a 15-year-old $46, \mathrm{XY}$ female patient with a premature termination in the steroidogenic acute regulatory protein causing congenital lipoid adrenal hyperplasia. Journal of Clinical Endocrinology and Metabolism 199984 1628-1632. (doi:10.1210/jc. 84.5.1628)

24 Tanae A, Katsumata N, Sato N, Horikawa R \& Tanaka T. Genetic and endocrinological evaluations of three 46,XX patients with congenital lipoid adrenal hyperplasia previously reported as having presented spontaneous puberty. Endocrine Journal 2000 47 629-634. (doi:10.1507/endocrj.47.629)

25 Shima M, Tanae A, Miki K, Katsumata N, Matsumoto S, Nakajima S, Harada T, Shinagawa T, Tanaka T \& Okada S. Mechanism for the development of ovarian cysts in patients with congenital lipoid adrenal hyperplasia. European Journal of Endocrinology 2000142 274-279. (doi:10.1530/eje.0.1420274)

26 Kaku U, Kameyama K, Izawa M, Yamada M, Miyamoto J, Suzuki T, Sasano H \& Hasegawa Y. Ovarian histologic findings in an adult patient with the steroidogenic acute regulator protein (StAR) deficiency reveal the impairment of steroidogenesis by lipoid deposition. Endocrine Journal 200855 1043-1049. (doi:10.1507/ endocrj.K08E-102)

27 Pall M, Azziz R, Beires J \& Pignatelli D. The phenotype of hirsute women: a comparison of polycystic ovary syndrome and 21-hydroxylase-deficient nonclassic adrenal hyperplasia. Fertility and Sterility 201094 684-689. (doi:10.1016/j.fertnstert.2009. 06.025)

28 Risma KA, Clay CM, Nett TM, Wagner T, Yun J \& Nilson JH. Targeted overexpression of luteinizing hormone in transgenic mice leads to infertility, polycystic ovaries, and ovarian tumors. PNAS 199592 1322-1326. (doi:10.1073/pnas.92.5.1322)

29 Sierralta WD, Kohen P, Castro O, Muñoz A, Strauss JF III \& Devoto L. Ultrastructural and biochemical evidence for the presence of mature steroidogenic acute 459 regulatory protein (StAR) in the cytoplasm of human luteal cells. Molecular and Cellular Endocrinology 2005242 103-110. (doi:10.1016/j.mce. 2005.08.003)

30 Devoto L, Kohen P, Muñoz A \& Strauss JF III. Human corpus luteum physiology 462 and the luteal-phase dysfunction associated with ovarian stimulation. Reproductive Biomedicine Online 200918 (Suppl 2) 19-24. (doi:10.1016/S1472-6483 (10)60444-0)

31 Hasegawa T, Zhao L, Caron KM, Majdic G, Suzuki T, Shizawa S, Sasano H \& Parker KL. Developmental roles of the steroidogenic acute regulatory protein (StAR) as 466 revealed by knock out mice. Molecular Endocrinology $2000 \quad 14 \quad 1462-1471$. (doi:10.1210/me.14.9.1462)

32 Jin HY, Choi JH, Lee BH, Kim GH, Kim HK \& Yoo HW. Ovarian cyst torsion in a patient with congenital lipoid adrenal hyperplasia. European Journal of Pediatrics 2011 170 535-538. (doi:10.1007/ s00431-010-1342-0)

33 Khoury K, Barbar E, Ainmelk Y, Ouellet A \& LeHoux JG. Gonadal function, first cases of pregnancy and child delivery in a woman 
with lipoid congenital adrenal hyperplasia (LCAH). Journal of Clinical Endocrinology and Metabolism 200994 1333-1337. (doi:10.1210/jc.2008-1694)

34 Muller J, Torsson A, Damkjaer Nielsen M, Petersen KE, Christoffersen J \& Skakkebaek NE. Gonadal development and growth in 46,XX and 46,XY individuals with P450scc deficiency (congenital lipoid adrenal hyperplasia). Hormone Research 1991 36 203-208. (doi:10.1159/000182162)

35 Kirkland RT, Kirkland JL, Johnson CM, Horning MG, Librik L \& Clayton GW. Congenital lipoid adrenal hyperplasia in an eight year old phenotypic female. Journal of Clinical Endocrinology and Metabolism 197336 488-496. (doi:10.1210/jcem-36-3-488)

36 Saenger P, Klonari Z, Black SM, Compagnone N, Mellon SH, Fleischer A, Abrams CA, Shackelton CH \& Miller WL. Prenatal diagnosis of congenital lipoid adrenal hyperplasia. Journal of Clinical Endocrinology and Metabolism $1995 \quad 80$ 200-205. (doi:10.1210/jc.80.1.200)

37 Saenger P. New developments in congenital lipoid adrenal hyperplasia and 486 steroidogenic acute regulatory protein. Pediatric Clinics of North America 199744 397-421. (doi:10.1016/ S0031-3955(05)70483-1)
38 Kim SO, Choi C, Kim CJ, Kwon D, Kang TW, Park K, Ryu SB, Jung SI, Oh KJ \& Im CM. Lipoid congenital adrenal hyperplasia: pathologic features of the testes. Urology $2010 \mathbf{7 5}$ 176-178. (doi:10.1016/j.urology.2009.04.073)

39 Abdulhadi-Atwan M, Jean A, Chung WK, Meir K, Ben Neriah Z, Stratigopoulos G, Oberfield SE, Fennoy I, Hirsch HJ, Bhangoo A et al. Role of a founder c.201_202delCT mutation and new phenotypic features of congenital lipoid adrenal hyperplasia in Palestinians. Journal of Clinical Endocrinology and Metabolism 2007 92 4000-4008. (doi:10.1210/jc.2007-1306)

40 Aitken LA, Lindan CE, Sidney S, Gupta N, Barkovich AJ, Sorel M \& Wu YW. Chiari type I malformation in a pediatric population. Pediatric Neurology 200940 449-454. (doi:10.1016/j.pediatrneurol.2009.01.003)

Received 13 July 2012

Revised version received 23 November 2012

Accepted 4 December 2012 